\title{
Hyperbolic Type Traveling Wave Solution of Vakhnenko-Parkes Equation
}

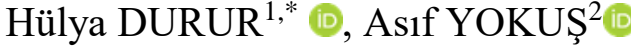 \\ 1,*'Department of Computer Engineering, Faculty of Engineering, Ardahan University, Ardahan, TURKEY \\ ${ }^{2}$ Department of Actuary, Faculty of Science, Firat University, Elazig, 23100, TURKEY.
}

Geliş / Received: 17/01/2020, Kabul / Accepted: 01/06/2020

\begin{abstract}
In this article, structure of $\left(1 / G^{\prime}\right)$-expansion method is applied. Another name of the reduced Ostrovsky equation, Vakhnenko-Parkes (V-P) equation is taken into consideration and exact solutions have been constructed of the (V-P) equation using $\left(1 / G^{\prime}\right)$-expansion method. This method is an easier and efficient method for finding analytic solutions of nPDEs. The method appears to be easier and faster for symbolic computation.
\end{abstract}

Keywords: $\left(1 / G^{\prime}\right)$-expansion method, the Vakhnenko-Parkes equation, exact solution, traveling wave solution.

\section{Vakhnenko-Parkes Denkleminin Hiperbolik Tipte Yürüyen Dalga Çözümü}

Öz

Bu makalede, $\left(1 / G^{\prime}\right)$-açılım metodunun yapısı uygulanmıştır. İndirgenmiş Ostrovsky denkleminin bir diğer adı olan Vakhnenko-Parkes (V-P) denklemi dikkate alınmış ve (V-P) denkleminin $\left(1 / G^{\prime}\right)$-açılım metodunu kullanılarak tam çözümleri inşa edilmiştir. Bu yöntem lineer olmayan kısmi diferansiyel denklemlerin analitik çözümlerini bulmak için daha kolay ve etkili bir metottur. Metot sembolik hesaplama için daha kolay ve daha hızlı görünüyor.

Anahtar Kelimeler: $\left(1 / G^{\prime}\right)$-açılım metodu, Vakhnenko-Parkes denklemi, tam çözüm, yürüyen dalga çözümü.

\section{Introduction}

nPDEs are studied in many areas such as in fluids science, engineering, and applied sciences. Many studies on analytical and numerical solutions have been done in literature for long years. A variety of methods are used for these studies. Some of these methods are Hirota bilinear method Manafian, (2018), The tanh-coth method Wazwaz (2007), $\left(G^{\prime} / G\right)$-expansion method Yokuş and Kaya (2015), Yokus and Tuz (2017), Durur
(2019), Sumudu transform method Yavuz and Özdemır (2018), extended sinh-Gordon equation expansion method Baskonus et al. (2018), Cattani et al. (2018), Sub equation method Durur et al. (2019), the ClarksonKruskal (CK) direct method Su-Ping and LiXin (2007), $\left(1 / G^{\prime}\right)$-expansion method Yokuş and Durur (2019), Yokuş and Kaya (2015), Durur and Yokuş (2019), the modified Kudryashov method Kumar et al. (2018), Adomian Decomposition methods 
Kaya and Yokus (2002), Kaya and Yokus (2005), Yavuz and Özdemir (2018), first integral method Darvishic et al. (2016), collocation method Aziz and Šarler (2010), new sub equation method Kurt et al. (2019), improved Bernoulli sub-equation function method Baskonus and Bulut (2016), Dusunceli (2019), residual power series method Durur et al. (2019), the modified expexpansion function method Yokus et al. (2018), Difference scheme method Faraj and Modanli (2017), newly extended direct algebraic technique Gao et al. (2020) and so on.

Vakhnenko-Parkes confirmed the reduced Ostrovsky equation may be converted to the new integrable equation (Vakhnenko and Parkes, 1998).

Consider the (V-P) equation Abazari (2010),

$u u_{x x t}-u_{x} u_{x t}+u^{2} u_{t}=0$

in the form.

Many scientists have been studied with (V-P) equation. Some of these are as follows: solutions of the (V-P) equation are obtained using the inverse scattering method Vakhnenko and Parkes (2012), with the help of exp-function and the $\exp -(-\phi(\xi))$ expansion method, the exact solutions of the (V-P) equation are obtained Roshid et al. (2014), two solitary wave solutions of (V-P) equation are attained using the ansatz method Majid et al. (2012), different type solutions of (V-P) equation are attained Ye et al. (2012), analytic solutions to the (V-P) equation using the complex method $\mathrm{Gu}$ et al. (2017), exact solutions of the (V-P) equation are obtained using the improved $\left(G^{\prime} / G\right)$ expansion method Liu and He (2013), different type solutions of the (V-P) equation are obtained with the aim of the Bernoulli sub-equation function method (Baskonus et al.,2015).

In this study, we are interested in the (V-P) equation. We have been obtained analytic solutions for the (V-P) equation using $\left(1 / G^{\prime}\right)$ expansion method.

\section{2. $\left(1 / G^{\prime}\right)$-Expansion Method}

Consider general form of NLPDEs

$T\left(u, \frac{\partial u}{\partial t}, \frac{\partial u}{\partial x}, \frac{\partial^{2} u}{\partial x^{2}}, \ldots\right)=0$.

Let

$u=u(x, t)=U(\xi), \quad \xi=k x+w t, w \neq 0$,

where $w, k$ are constants and $w$ is the velocity of the wave. We may be converted into following nODE for $U(\xi)$ :

$$
\mathrm{L}\left(U, U^{\prime}, U^{\prime \prime}, U^{\prime \prime \prime}, \ldots\right)=0 \text {. }
$$

The solution of Eq. (3) is assumed to have the form

$U(\xi)=a_{0}+\sum_{i=1}^{n} a_{i}\left(\frac{1}{G^{\prime}}\right)^{i}$,

where $a_{i}$ are constants, $n$ is a positive integer which is the equilibrium term in Eq. (3) and $G=G(\xi)$ provides the following secondorder IODE

$G^{\prime \prime}+\lambda G^{\prime}+\mu=0$,

where $\lambda$ and $\mu$ are constants to be determined after

$\frac{1}{G^{\prime}[\xi]}=\frac{1}{-\frac{\mu}{\lambda}+A \cos h[\xi \lambda]-A \sin h[\xi \lambda]}$

where $A$ is an integral constant. If the desired derivatives of the Eq. (4) are calculated and replacing in the Eq. (3), a polynomial with the argument $\left(1 / G^{\prime}\right)$ is attained. An algebraic 
equation system is created by equalizing the coefficients of this polynomial to zero. These equations are solved using the package program and put into place in the default Eq. (3) solution function. Thus, the solutions of Eq. (1) are attained.

\section{Solutions of the (V-P) equation}

We consider Eq. (1) and using transformation $u=u(x, t)=U(\xi), \quad \xi=k x+w t, w \neq 0$,

where $w, k$ are constants

$k^{2} w U U^{\prime \prime \prime}-k^{2} w U^{\prime} U^{\prime \prime}+w U^{2} U^{\prime}=0$.

If the Eq. (7) is integrated according to $\xi$, we can write the following equation

$3 k^{2} U U^{\prime \prime}-3 k^{2}\left(U^{\prime}\right)^{2}+U^{3}=0$.

Here, the integral constant is zero. According to the homogeneous balancing principle, the equilibrium term of Eq. (8) is $n=2$ and the following situation is obtained in Eq. (4),

$$
U(\xi)=a_{0}+a_{1}\left(\frac{1}{G^{\prime}[\xi]}\right)+a_{2}\left(\frac{1}{G^{\prime}[\xi]}\right)^{2}, a_{2} \neq
$$

0.

Replacing Eq. (9) into Eq. (8) and the coefficients of Eq. (1) are equal to zero, we may establish the following algebraic equation systems

Const: $a_{0}^{3}=0$,

$$
\begin{aligned}
& \frac{1}{G^{\prime}[\xi]}: 3 k^{2} \lambda^{2} a_{0} a_{1}+3 a_{0}^{2} a_{1}=0 \\
& \frac{1}{G^{\prime}[\xi]^{2}}: 9 k^{2} \lambda a_{0} a_{1}+3 a_{1}^{2} a_{0}+12 k^{2} \lambda^{2} a_{0} a_{2} \\
& +3 a_{0}^{2} a_{2}=0
\end{aligned}
$$

$$
\begin{aligned}
\frac{1}{G^{\prime}[\xi]^{3}}: 6 k^{2} \mu^{2} & a_{0} a_{1}+3 k^{2} \lambda \mu a_{1}^{2}+a_{1}^{3} \\
& +30 k^{2} \lambda \mu a_{0} a_{2}+3 k^{2} \lambda^{2} a_{1} a_{2} \\
& +6 a_{0} a_{1} a_{2}=0
\end{aligned}
$$$$
\frac{1}{G^{\prime}[\xi]^{4}}: 3 k^{2} \mu^{2} a_{1}^{2}+18 k^{2} \mu^{2} a_{0} a_{2}+
$$$$
15 k^{2} \lambda \mu a_{1} a_{2}+3 a_{1}^{2} a_{2}+3 a_{0} a_{2}^{2}=0 \text {, }
$$

$\frac{1}{G^{\prime}[\xi]^{5}}: 12 k^{2} \mu^{2} a_{1} a_{2}+6 k^{2} \lambda \mu a_{2}^{2}+3 a_{1} a_{2}^{2}$ $=0$,

$\frac{1}{G^{\prime}[\xi]^{6}}: 6 k^{2} \mu^{2} a_{2}^{2}+a_{2}^{3}=0$.

\section{Case1.}

$a_{0}=0, a_{1}=-6 k^{2} \lambda \mu, a_{2}=-6 k^{2} \mu^{2}, \xi=$

$k x+w t$,

replacing values Eq. (11) into Eq. (9) and obtain the following hyperbolic wave solutions for Eq. (1):

$u(x, t)=-\frac{6 k^{2} \mu^{2}}{\left(-\frac{\mu}{\lambda}+A \operatorname{Cosh}[\lambda \xi]-A \operatorname{Sinh}[\lambda \xi]\right)^{2}}-$

$\frac{6 k^{2} \lambda \mu}{-\frac{\mu}{\lambda}+A \operatorname{Cosh}[\lambda \xi]-A \operatorname{Sinh}[\lambda \xi]}$.

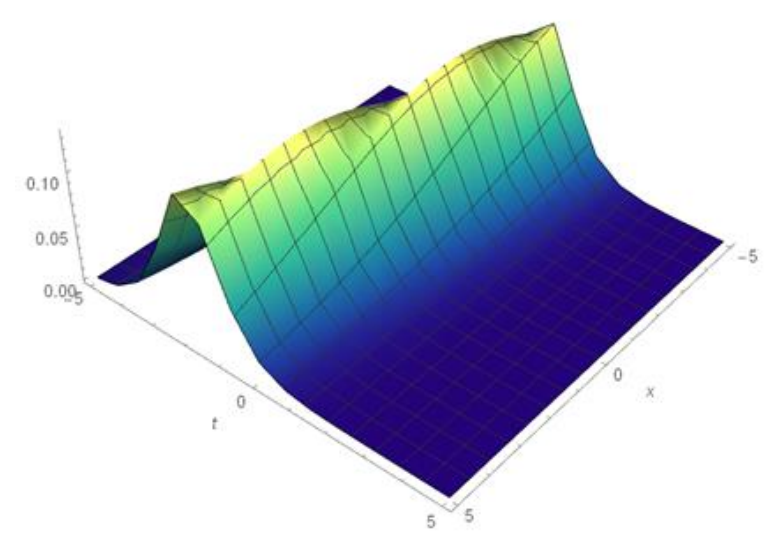



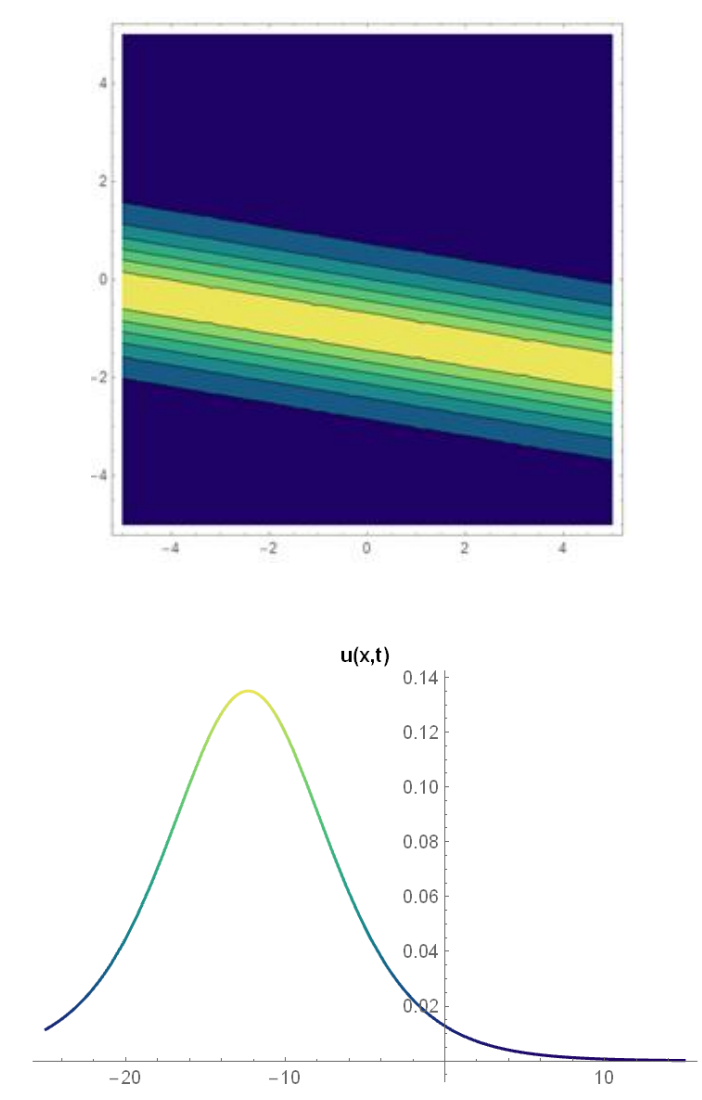

Figure 1. 3D, contour and 2D graphs of $\mathrm{u}(x, t)$ respectively for $\mu=-2, \lambda=3, \mathrm{w}=$ $0.6, k=0.1, A=0.1$.

\section{Conclusion}

In this letter, the new hyperbolic traveling wave solution of (V-P) equation has been obtained using $\left(1 / G^{\prime}\right)$-expansion method. The biggest advantage of the $\left(1 / G^{\prime}\right)$-expansion method is that it can be easily applied to many nonlinear partial differential equations. In addition, the systems of equations obtained by many expansion methods are simpler. It is a reliable and powerful method in obtaining traveling wave solutions. The disadvantage of this method is the production of a uniform wave solution. The solutions obtained are hyperbolic traveling wave solutions and are in Eq. (6) format.
Moreover, the computer package program has been used for computations and graphics in this study.

\section{References}

Manafian, J. (2018). "Novel solitary wave solutions for the $(3+1)$-dimensional extended Jimbo-Miwa equations". Computers \& Mathematics with Applications, 76(5), 12461260.

Wazwaz, A. M. (2007). "The tanh-coth method for solitons and kink solutions for nonlinear parabolic equations". Applied Mathematics and Computation, 188(2), 14671475 .

Yokuş, A., \& Kaya, D. (2015). “Traveling wave solutions of some nonlinear partial differential equations by using extendedexpansion method".

Yokus, A., \& Tuz, M. (2017). “An application of a new version of $\left(\mathrm{G}^{\prime} / \mathrm{G}\right)$-expansion method". In AIP Conference Proceedings (Vol. 1798, No. 1, p. 020165). AIP Publishing.

Durur, H. (2019). "Different types analytic solutions of the $(1+1)$-dimensional resonant nonlinear Schrödinger's equation using $\left(\mathrm{G}^{\prime} / \mathrm{G}\right)$-expansion method". Modern Physics Letters B, 2050036.

Yavuz, M., \& Özdemır, N. (2018). “An Integral Transform Solution for Fractional 
Advection-Diffusion

Problem". Institute of Science and Technology, 21(2), Mathematical Studies and Applications, 442. 590-599.

Baskonus, H. M., Sulaiman, T. A., Bulut, H., Yokuş, A., \& Kaya, D. (2015). “Conservation \& Aktürk, T. (2018). "Investigations of dark, bright, combined dark-bright optical and other soliton solutions in the complex cubic nonlinear Schrödinger equation with $\delta$ potential". Superlattices and Microstructures, $115,19-29$.

Cattani, C., Sulaiman, T. A., Baskonus, H. M., \& Bulut, H. (2018). "On the soliton solutions to the Nizhnik-Novikov-Veselov and the Drinfel'd-Sokolov systems". Optical and Quantum Electronics, 50(3), 138.

Durur, H., Taşbozan, O., Kurt, A., \& Şenol, M. (2019). "New Wave Solutions of Time Fractional Kadomtsev-Petviashvili Equation Arising In the Evolution of Nonlinear Long Waves of Small Amplitude". Erzincan University Journal of the Institute of Science and Technology, 12(2), 807-815.

Su-Ping, Q., \& Li-Xin, T. (2007). "Modification of the Clarkson-Kruskal Direct Method for a Coupled System". Chinese Physics Letters, 24(10), 2720.

Yokuş, A., \& Durur, H. (2019). "Complex hyperbolic traveling wave solutions of Kuramoto-Sivashinsky equation using (1/G') expansion method for nonlinear dynamic theory". Journal of Ballkesir University laws and a new expansion method for sixth order Boussinesq equation". In AIP Conference Proceedings (Vol. 1676, No. 1, p. 020062). AIP Publishing.

Durur, H., \& Yokuş, A. (2019). “(1/G')Açılım Metodunu Kullanarak Sawada-Kotera Denkleminin Hiperbolik Yürüyen Dalga Çözümleri”. Afyon Kocatepe Üniversitesi Fen Ve Mühendislik Bilimleri Dergisi, 19(3), 615619.

Kumar, D., Seadawy, A. R., \& Joardar, A. K. (2018). "Modified Kudryashov method via new exact solutions for some conformable fractional differential equations arising in mathematical biology". Chinese journal of physics, 56(1), 75-85.

Kaya, D., \& Yokus, A. (2002). “A numerical comparison of partial solutions in the decomposition method for linear and nonlinear partial differential equations". Mathematics and Computers in Simulation, 60(6), 507-512.

Kaya, D., \& Yokus, A. (2005). "A decomposition method for finding solitary and periodic solutions for a coupled higherdimensional Burgers equations". Applied Mathematics and Computation, 164(3), 857864. 
Yavuz, M., \& Özdemir, N. (2018). “A quantitative approach to fractional option pricing problems with decomposition series". Konuralp Journal of Mathematics, 6(1), 102109.

Darvishi, M., Arbabi, S., Najafi, M., \& Wazwaz, A. (2016). "Traveling wave solutions of a (2+1)-dimensional Zakharovlike equation by the first integral method and the tanh method". Optik, 127(16), 6312-6321.

Aziz, I., \& Šarler, B. (2010). “The numerical solution of second-order boundary-value problems by collocation method with the Haar wavelets". Mathematical and Computer Modelling, 52(9-10), 1577-1590.

Kurt, A., Tasbozan, O., \& Durur, H. (2019). "The Exact Solutions of Conformable Fractional Partial Differential Equations Using New Sub Equation Method". Fundamental Journal of Mathematics and Applications, 2(2), 173-179.

Baskonus, H. M., \& Bulut, H. (2016). "Exponential prototype structures for $(2+1)$ dimensional Boiti-Leon-Pempinelli systems in mathematical physics". Waves in Random and Complex Media, 26(2), 189-196.

Dusunceli, F. (2019). "New Exact Solutions for Generalized $(3+1)$ Shallow Water-Like (SWL) Equation". Applied Mathematics and Nonlinear Sciences, 4(2), 365-370.
Durur, H., Şenol, M., Kurt, A., \& Taşbozan, O. (2019). "Zaman-Kesirli KadomtsevPetviashvili Denkleminin Conformable Türev ile Yaklaşık Çözümleri”. Erzincan University Journal of the Institute of Science and Technology, 12(2), 796-806.

Yokus, A., Baskonus, H. M., Sulaiman, T. A., \& Bulut, H. (2018). "Numerical simulation and solutions of the two-component second order KdV evolutionarysystem". Numerical Methods for Partial Differential Equations, 34(1), 211-227.

Vakhnenko, V. O., \& Parkes, E. J. (1998). "The two loop soliton solution of the Vakhnenko equation". Nonlinearity, 11(6), 1457.

Abazari, R. (2010). “Application of G' Gexpansion method to travelling wave solutions of three nonlinear evolution equation". Computers \& Fluids, 39(10), 19571963.

Vakhnenko, V. O., \& Parkes, E. J. (2012). "Solutions associated with discrete and continuous spectrums in the inverse scattering method for the Vakhnenko-Parkes equation". Progress of Theoretical Physics, 127(4), 593613.

Roshid, H. O., Kabir, M. R., Bhowmik, R. C., \& Datta, B. K. (2014). "Investigation of Solitary wave solutions for VakhnenkoParkes equation via exp-function and Exp (- 
$\phi(\xi))$-expansion method". SpringerPlus, 3(1), Solution of Telegraph Partial Differential 692. Equation”.

Majid, F., Triki, H., Hayat, T., Aldossary, O. Gao, W., Rezazadeh, H., Pinar, Z., Baskonus, M., \& Biswas, A. (2012). "Solitary wave H. M., Sarwar, S., \& Yel, G. (2020). "Novel solutions of the Vakhnenko-Parkes equation”. explicit solutions for the nonlinear Zoomeron Nonlinear Analysis: Modelling and Control, equation by using newly extended direct $17(1), 60-66$. algebraic technique". Optical and Quantum

Volterra V. (1959). "Theory of Functionals Electronics, 52(1), 1-13.

and of Integral and Integro-differential Equations". Dover Publications, New York.

Ye, Y., Song, J., Shen, S., \& Di, Y. (2012). "New coherent structures of the VakhnenkoParkes equation". Results in Physics, 2, 170174.

Gu, Y., Yuan, W., Aminakbari, N., \& Jiang, Q. (2017). "Exact solutions of the Vakhnenko-Parkes equation with complex method". Journal of Function Spaces.

Baskonus, H. M., Bulut, H., \& Emir, D. G. (2015). "Regarding New Complex Analytical Solutions for the Nonlinear Partial Vakhnenko-Parkes Differential Equation via Bernoulli Sub-Equation Function Method". Mathematics Letters, 1, 1-9.

Liu, X., \& He, C. (2013). "New Traveling Wave Solutions to the Vakhnenko-Parkes Equation”. ISRN Mathematical Physics.

Faraj, B., \& Modanli, M. (2017). "Using Difference Scheme Method for the Numerical 